\title{
Inulin, oligofructose and immunomodulation
}

\author{
Bernhard Watzl*, Stephanie Girrbach and Monika Roller \\ Institute of Nutritional Physiology, Federal Research Centre for Nutrition and Food, Haid-und-Neu-Strasse 9, 76131 Karlsruhe, Germany
}

\begin{abstract}
Diet is known to modulate immune functions in multiple ways and to affect host resistance to infections. Besides the essential nutrients, non-essential food constituents such as non-digestible carbohydrates may also have an impact on the immune system, especially in the area of the gut-associated lymphoid tissue (GALT). Recent data now provide first evidence that prebiotics such as inulin/oligofructose (IN/OF) modulate functions of the immune system. In animal studies IN/OF primarily activated immune cells in Peyer's patches including IL-10 production and natural killer (NK) cell cytotoxicity. Other immune functions modulated by IN/OF included the concentration of secretory IgA in ileum and caecum, splenic NK cell cytotoxicity as well as splenocyte cytokine production. In different tumour models, a lower incidence of tumours was observed, which in the case of colonic tumours was associated with enhanced NK cell cytotoxicity in the GALT. Few human studies so far have investigated the effects of IN/OF alone or in combination with other dietary supplements on immunocompetence. Supplementation of IN/OF resulted in minor changes of systemic immune functions such as decrease in phagocytic activity. No data are available on the effects of IN/OF on the GALT in man. The mechanisms of the reported effects of IN/OF on the immune system are currently investigated and include: (i) direct effects of lactic acid-producing bacteria or bacterial constituents on immune cells; (ii) the production of SCFA and binding to SCFA receptors on leucocytes. In conclusion, the current data suggest that IN/OF primarily modulate immune parameters in the GALT, but splenocytes are also activated by IN/OF. Human studies are needed to find out whether IN/OF have the potential to modulate systemic immunity in wellnourished individuals and to lower the risk of diseases such as colon cancer.
\end{abstract}

Inulin: Oligofructose: Prebiotic: Immune system: Gut-associated lymphoid tissue

Diet is known to modulate immune functions in man in multiple ways and for essential nutrients a number of human studies have demonstrated a beneficial role within the immune system (Calder et al. 2002). In contrast, the impact of non-essential food constituents on immunocompetence has not been studied thoroughly. These constituents include phytochemicals, microbial products of food fermentation (probiotics and their metabolites) and prebiotics. For the proper functioning of the immune system, the intestinal microflora plays an important role. Its composition is largely dependent on dietary constituents including prebiotics. Besides the effects of non-digestible carbohydrates such as prebiotics on the number and composition of the intestinal microflora, their metabolites may further affect the gut-associated lymphoid tissue (GALT). Prebiotics occur naturally in plant food and have recently become a constituent of an increasing number of foods. First data now indicate that prebiotics may modulate the systemic immune system as well as the local immune system in the gut.

\section{Inulin and oligofructose}

Chemically, inulin (IN) and oligofructose (OF) can be defined as polydisperse fructans. Fructans in IN are typically linked by $\beta(2 \rightarrow 1)$-fructofuranosyl bonds with a glucose moiety typically resident at the end of almost each fructose chain, and also contain a small branched-chain fraction (1-2\% of $\beta-2,6$-linkages; van Loo et al. 1995). OF is always present in IN, a blend of fructose oligomers and polymers, and differs from IN in regard to its degree of polymerisation (DP; $2<\mathrm{DP}<10$ for OF; $2<\mathrm{DP}<$ 60 for IN). OF can be produced from IN by controlled partial enzymatic hydrolysis of IN, e.g. from chicory roots (Flickinger et al. 2003). IN and OF are widespread plant storage carbohydrates in vegetables (chicory root, Jerusalem artichoke, onion, garlic, leek, asparagus), cereals (wheat, rye, barley) and fruit (banana; van Loo et al. 1995). They are added to food due to their technological benefits (fat and sugar replacement, organoleptic properties, texture improvement; Franck, 2002) or used as supplements due to their various functional properties (improvement of mineral absorption, impact on bowel habit, interaction with lipid metabolism, preventive effect against colon cancer; van Loo et al. 1999). A main characteristic effect of IN-type fructans is their prebiotic property. As neither mammalian pancreatic nor brush border enzymes are able to hydrolyse the $\beta$-2,1-linkage, IN and OF escape digestion in the small intestine and reach the colon virtually intact where they then undergo fermentation by the resident microbiota and stimulate bifidobacteria growth, resulting in an increased production of SCFA (Schneeman, 1999; Delzenne, 2003).

\section{Overview of the immune system}

The immune system guards the body against foreign substances and protects from invasion by pathogenic organisms. It can be divided into two arms: the innate or non-specific immune system and the acquired or specific immune system.

Abbreviations: AOM, azoxymethane; DP, degree of polymerisation; FAE, follicle-associated epithelium; GALT, gut-associated lymphoid tissue; GOS, galactooligosaccharides; IEL, intraepithelial lymphocytes; IFN- $\gamma$, interferon-gamma; IN, inulin; LP, lamina propria; NK, natural killer; OF, oligofructose; PP, Peyer's patches; PRR, pattern recognition receptors; TLR, toll-like receptors.

* Corresponding author: Dr Bernhard Watzl, fax +49 7216625 404, email bernhard.watzl@bfe.uni-karlsruhe.de 
The innate immune system acts as a first line of defence by preventing the entry of infectious agents or by eliminating invaded pathogens. It comprises physical barriers such as skin or mucous membranes as well as cells in blood and tissue, e.g. phagocytes or natural killer (NK) cells, but also soluble mediators like complement proteins or cytokines. A challenge to the innate immune system often leads to the activation of the acquired immune system. This system consists of two major cell types, the $\mathrm{T}$ - and B-lymphocytes, which enable the specific recognition of and response to invaders. Each B-cell is programmed to produce one type of antibody matching only one specific antigen, so B-lymphocytes represent a part of the memory of the immune system. T-lymphocytes develop into functionally different cell types with specific cytokine patterns: $\mathrm{CD} 4{ }^{+} \mathrm{T}-$ helper (Th), CD8 ${ }^{+} \mathrm{T}$-suppressor cells (Ts) or cytotoxic (CTL) and regulatory $\mathrm{CD}^{+} / \mathrm{CD} 25^{+} \mathrm{T}$-cells $\left(\mathrm{T}_{\text {reg; }}\right.$; Janeway et al. 2001). The Th subset is further divided into Th1 cells, which secrete cytokines such as IL-2 and interferon-gamma (IFN- $\gamma$ ) and mediate immunity to intracellular pathogens, and into Th2 cells. These cells are responsible for mediating immunity to extracellular pathogens and stimulate antibody production by the secretion of cytokines such as IL-4 and IL-13 (Janeway et al. 2001; Jankovic et al. 2001; McGuirk \& Mills, 2002; Mowat, 2003). CTL provide for the direct killing of virally infected cells and are able to suppress responses of Th-lymphocytes (Janeway et al. 2001). Immunosuppressive functions are also attributed to $\mathrm{T}_{\text {reg-cells with a }}$ cytokine profile distinct from either Th1 or Th2 cells (e.g. TGF- $\beta$ and IL-10). After antigenic stimulation $\mathrm{T}_{\text {reg-lymphocytes }}$ can specifically inhibit the immune response of Th cells (Iijima et al. 2001; Janeway et al. 2001; McGuirk \& Mills, 2002).

The largest immune organ is situated in the gut where continuous exposure to diverse antigens takes place. The GALT contains about $60 \%$ of all lymphocytes in the body and is compartmentalised into inductive and effector sites of aggregated (e.g. Peyer's patches (PP)) and non-aggregated cells (e.g. lamina propria (LP) and intraepithelial lymphocytes (IEL)) forming a unique immune network (Mowat \& Viney, 1997; Iijima et al. 2001; Fig. 1). PP are lymphoid aggregates in the submucosa separated from the lumen by the 'follicle-associated epithelium' (FAE). The FAE contains specialised epithelial cells, M-cells, which are responsible for the uptake and transport of antigen into the underlying lymphatic tissue where it is presented to dendritic, T- and B-cells. Lymphocytes activated within the inductor region of PP disseminate via mesenteric lymph nodes, the crossroads between peripheral and mucosal recirculation, migrate into the bloodstream through the thoracic duct and finally return to mucosal sites (Mowat, 2003). The layer of connective tissue between the epithelium and the muscularis mucosae forms the LP and comprises B-cells (memory cells as well as IgA-producing plasma cells), mast cells, dendritic cells, macrophages and T-cells of mainly Th function (MacDonald, 2003). IEL, another arm of the effector site of the GALT, are located between epithelial cells along the small and large intestine and therefore directly facing the bowel lumen - they represent the first component of the mucosal immune system to encounter bacterial and food antigens. In contrast to LP leucocytes, IEL are a population of mainly CTL and suppressor-type T-lymphocytes. They help to eliminate infected or transformed epithelial cells and play a crucial role in the maintenance of oral tolerance, the unresponsiveness of systemic lymphoid organs to harmless foreign antigens (for example, food-borne), while sustaining protection against pathogens (Abreu-Martin \& Targan, 1996; Iijima et al. 2001; MacDonald, 2003).

\section{Immunomodulatory effects of inulin and oligofructose}

\section{Human studies}

The direct effects of prebiotics on the human immune system have so far only been investigated in a few studies (Schley \& Field, 2002). In a study with elderly people living in a nursing home, 3 weeks of OF supplementation at a dose of twice $4 \mathrm{~g} / \mathrm{d}$ increased faecal bacterial counts of bifidobacteria (Guigoz et al. 2002). The percentage of $\mathrm{CD}^{+}, \mathrm{CD} 4^{+}$and $\mathrm{CD} 8^{+}$lymphocytes was raised compared to controls. In contrast, phagocytic activity of peripheral blood granulocytes and monocytes as well as the expression of IL-6 mRNA in monocytes was decreased. The authors speculate that

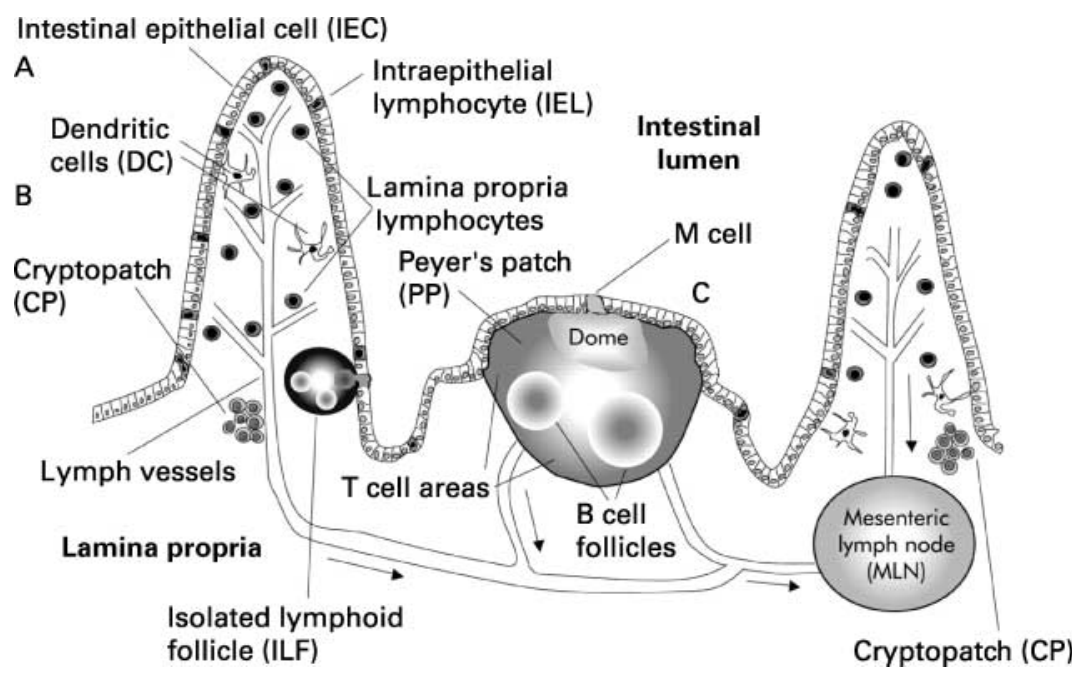

Fig. 1. Schematic overview of the lymphoid elements of the gut-associated lymphatic system. Peyer's patches (PP) and mesenteric lymph nodes (MLN) are organised intestinal lymphoid follicles. $(A-C)$ Pathways of intestinal antigen uptake: luminal antigen can be taken up by $(A)$ intestinal epithelial cells, (B) interdigitating lamina propria dendritic cells, and by (C) M cells. The lymphatic drainage of PP and villus lamina propria goes to the MLN (direction of lymph flow indicated by arrows). (From Spahn \& Kucharzik, 2004.) 
due to a possible reduction in pathogenic bacteria induced by $\mathrm{OF}$ supplementation, inflammatory processes such as phagocytosis and IL-6 production were decreased. However, the study did not include a time control; therefore, the possibility that the finding arose by chance cannot be excluded. A study in free-living elderly receiving a nutritional supplement with placebo or with $\mathrm{OF}(6 \mathrm{~g} / \mathrm{d})$ for a period of 28 weeks investigated the immune response to vaccination with influenza and pneumococcal vaccines (Bunout et al. 2002). No differences in serum antibodies between placebo and $\mathrm{OF}+$ nutrient supplement were observed after vaccination. Ex vivo, mononuclear cells showed similar lymphocyte proliferative responses and cytokine secretion capacities (IL-4, IFN- $\gamma$ ). Since there was no study group which received the OF alone, it is difficult to separate the effects of the nutrient supplement that provided $50 \%$ of vitamin daily reference values from the effects of OF. Elderly subjects with adequate nutrition are known to have appropriate immune functions that cannot be further stimulated by dietary supplements (Watzl et al. 2000). In a study with infants (aged 6-12 months) $\mathrm{OF}(0.67 \mathrm{~g} / \mathrm{d})$ in combination with a cereal supplement had no effect on diarrhoea prevalence and antibody titres to Haemophilus influenza compared to the cereal supplement alone (Duggan et al. 2003). Since $87 \%$ of the children were breast-fed, human milk may have provided adequate amounts of oligosaccharides to exert prebiotic effects in the gut. Two studies have looked at the effect of the combined application of probiotics with a galactooligosaccharide (GOS; Chiang et al. 2000; Sheih et al. 2001). While GOS in combination with Bifidobacterium lactis enhanced NK cell activity compared to the probiotic alone, GOS in combination with Lactobacillus rhamnosus HNO01 was not significantly different from the probiotic alone. Neither study included a prebiotic group alone or was controlled for time effects, so conclusions regarding the immunomodulatory potential of GOS cannot be drawn. In summary, only one human study so far has investigated the effects of $\mathrm{OF}$ alone on the immune system. More human studies including dose-response studies with prebiotics such as IN/OF are needed, since the demonstrated change in microflora composition associated with IN/OF intake (Kaur \& Gupta, 2002) is expected to modulate the activity of the GALT.

\section{Animal studies}

OF ( $3 \mathrm{~g} / \mathrm{d})$ in combination with Lactobacillus paracase $i$ was given to piglets either $10 \mathrm{~d}$ after birth or $10 \mathrm{~d}$ after weaning (Herich et al. 2002). After birth, the combined treatment (synbiotic) resulted in reduced phagocytic activity compared with control. When compared to the probiotic group, the synbiotic supplement resulted in lower numbers of leucocytes, lymphocytes and monocytes in the blood. After weaning, no significant differences between groups were observed. Since there was no pure OF group, it is speculative to discuss whether OF modulated phagocytic activity and leucocyte numbers in these piglets. A study with rotavirus-challenged mice treated with a combination of bifidobacteria and an OF supplement also found no differences in diarrhoea incidence and faecal $\operatorname{Ig} \mathrm{A}$ when compared to the probiotic alone. Again, a pure OF group was not included in the study (Qiao et al. 2002). Buddington et al. (2002) exposed mice supplemented with $\mathrm{OF}(10 \%, \mathrm{w} / \mathrm{w})$ or IN $(10 \%, w / w)$ to enteric and systemic pathogens or to different tumour inducers. The incidence of lung tumours after injection of B16F10 tumour cells was not affected by the prebiotic supplements. However, carcinogen-induced aberrant crypt foci in the distal colon were reduced in rats supplemented with OF or IN.
Pathogen exposure in OF- and IN-supplemented rats resulted in reduced mortality compared to cellulose-supplemented controls $(10 \%, \mathrm{w} / \mathrm{w})$. Taken together, these data suggest that OF and IN enhance immunity against these pathogens and against aberrant cells in the colon. In a follow-up study these authors investigated the modulatory effects of these prebiotics at a similar dose on immune functions in mice (Kelly-Quagliana et al. 2003). After a period of 6 weeks with OF and IN supplementation, both prebiotics increased NK cell activity compared to the cellulose group. Lymphocyte subpopulations and faecal IgA did not differ between groups, while phagocytic activity of peritoneal macrophages was stimulated in mice fed either prebiotic. Since control mice received cellulose, and intestinal cellulose degradation differs from intestinal IN/OF fermentation, it is difficult to ascribe the observed changes to a decrease in cellulose intake or an increase in prebiotic intake.

OF obtained by enzymatic synthesis from sucrose has also been classified as prebiotic (Gibson \& Roberfroid, 1995; Grizard \& Barthomeuf, 1999). This OF given to mice for a period of 4 weeks $(2.5$ and $7.5 \%)$ resulted in minor effects on the immune system (Hosono et al. 2003). However, ex vivo culture of immune cells isolated from PP of these OF-fed mice together with sonicated Bifidobacterium pseudocatenulatum resulted in increased concentrations of total IgA, IFN- $\gamma$, IL-5, IL-6 and IL-10 compared to mice without OF supplementation. Furthermore, the size of PP in the small intestine was increased in mice supplemented with 2.5 or $7.5 \%$ OF without changing the cell number (Hosono et al. 2003). Several other studies also observed a change in PP cellularity. In the Min mouse model OF supplementation $(5.8 \%)$ resulted in significantly higher numbers of macroscopically detectable lymphoid nodules in the small intestine (Pierre et al. 1997). In another mouse study $16 \mathrm{~d}$ of OF supplementation $(10 \%)$ elevated the total cell number in PP (Manhart et al. 2003). While the number of $\mathrm{CD}^{+}$and $\mathrm{CD} 8^{+}$ T-lymphocytes was not affected by $\mathrm{OF}$, a significantly higher number of B-lymphocytes was detected in PP compared to controls. These studies suggest that OF fermentation in the large intestine induces changes in distant compartments of the GALT. Bacteria in the terminal ileum may also contribute to OF fermentation, but this has not been proven so far.

In mice infected with Clostridium difficile and treated with an antibiotic, OF supplementation ( $30 \mathrm{~g} / \mathrm{l}$ drinking-water) increased macrophage numbers in caecum and colon without affecting prostaglandin $\mathrm{E}_{2}$ production of the macrophages (Gaskin et al. 1996). In the Min mouse model with tumours occurring primarily in the small intestine, OF reduced the incidence of colon tumours (Pierre et al. 1997). Interestingly, mice depleted in $\mathrm{CD}^{+}$and $\mathrm{CD}^{+}$lymphocytes had significantly more tumours than immunocompetent mice (Pierre et al. 1999) suggesting that reduction of colonic tumour incidence after OF feeding requires a normal functioning immune system. In a follow-up study, the effect of OF on cytokine mRNA expression in Min mouse colons was studied (Bassonga et al. 2001). mRNA expression of IL-4, IL-5, IL-13 and IFN- $\gamma$ was not affected by OF supplementation, while IL-15 mRNA expression was significantly enhanced.

\section{Immunomodulatory effects of oligofructose-enriched inulin}

Short- and long-term studies from our laboratory with F344 rats indicate that OF-enriched IN primarily modulates immune functions in the GALT. In both studies, a high-fat, low-fibre 
diet was used as the control diet. The sources of carbohydrates in the control diet were sucrose and maltodextrins. The prebiotic group was fed the control diet supplemented with $10 \%$ OFenriched IN (which is a 1:1 mixture of long- and short-chain fractions of IN, extracted from chicory roots). The synbiotic group was fed a similar diet as the prebiotic group diet supplemented with $L$. rhamnosus $\mathrm{GG}$ and $B$. lactis $\mathrm{Bb} 12$ to provide $\sim 5 \times 10^{11}$ cfu of each strain per $\mathrm{kg}$ of diet. After a feeding period of 4 weeks, functions of immune cells isolated from the major immune organs including blood, spleen, mesenteric lymph nodes and PP were investigated. In addition, secretory immunoglobulin A (sIgA) in ileum and in caecum was quantified. No significant differences in the proportion of $\mathrm{CD} 4^{+}$and $\mathrm{CD} 8^{+}$ T-lymphocytes (all tissues), lymphocyte proliferation (all tissues), NK cell cytotoxicity (all tissues), neutrophil and monocyte phagocytosis (blood and spleen) as well as in neutrophil oxidative burst activity (blood) were observed between groups (Roller et al. 2004a). In contrast, OF-enriched IN supplementation significantly increased the production of IL-10 in PP compared with controls fed the high-fat, low-fibre control diet $(0.56 \pm 0.38 \mu \mathrm{g} / \mathrm{l} v$. $0 \cdot 31 \pm 0.13 \mu \mathrm{g} / \mathrm{l}, P<0 \cdot 05)$. The production of IL-10 was highly correlated with the production of IFN- $\gamma(r=0.90 ; P<0.0001)$ suggesting that the prebiotic supplement simultaneously activated different T-lymphocyte subpopulations and/or dendritic cells of the GALT. The synbiotic treatment significantly enhanced the production of $\operatorname{sIg} \mathrm{A}$ in the ileum $\left(1.30 \pm 0.75 \mathrm{OD}_{450} v\right.$. $\left.0.78 \pm 0.36 \mathrm{OD}_{450}, P<0.05\right)$, while the prebiotic treatment increased $\operatorname{sIgA}$ in the caecum $\left(1 \cdot 15 \pm 0.77 \mathrm{OD}_{450} v .0 .66 \pm 0.42\right.$ $\left.\mathrm{OD}_{450}, P<0 \cdot 05\right)$. Probably, the availability of prebiotics in the ileum supported the growth of the simultaneously supplemented probiotics and consequently stimulated $\operatorname{sIgA}$ synthesis. In contrast, in caecum with a high quantity of endogenous micro-organisms, prebiotic if applied alone supported growth of these bacteria which also stimulated sIgA production. In synbiotic-treated rats, however, prebiotics may have already been metabolised in the ileum and therefore could not further support bacterial growth in the caecum. Our results are in line with findings of a recent study demonstrating that feeding of $\mathrm{OF}$ to mice increased faecal IgA concentration (Hosono et al. 2003).

In the long-term study ( 33 weeks) we focused on the effects of prebiotics and synbiotics on the incidence of colonic tumours and on immune parameters within the same animals in a rat model of colon carcinogenesis (Roller et al. 2004b). The basic diet as well as the prebiotic- and synbiotic-supplemented diets were the same as in the short-term study. Ten days after beginning feeding the experimental diets, a number of the rats were administered the colon carcinogen azoxymethane (AOM). In all groups four or five animals were treated with saline instead of AOM and served as control for the carcinogen treatment. Supplementation of the control diet with the OF-enriched IN reduced the incidence of colonic tumours (Femia et al. 2002). The AOM treatment by itself reduced NK cell activity in all tissues investigated. Prebiotic (PP) and synbiotic (PP and spleen) supplementation prevented this AOM-associated suppression of NK cell activity, indicating a stimulatory potential of OF-enriched IN under these conditions. In addition, PP of synbiotic-supplemented rats exposed to AOM showed significantly higher NK cell activity compared with controls $(42 \pm 6 \%$ v. $32 \pm 6 \%, P<0.05)$. In rats without AOM treatment OF-enriched IN stimulated NK cell activity in the spleen $(43 \pm 10 \%$ v. $31 \pm 4 \%$ in controls, $P<0.05)$. In rats without AOM treatment prebiotic reduced the CD4:CD8 ratio in spleen compared with animals in the control group $(7.9 \pm 1.8$ v. $13.5 \pm 2.4 ; P<0.01)$ without significantly changing the percentage of $\mathrm{CD}^{+}$and $\mathrm{CD} 8^{+}$T-lymphocytes. In AOM-exposed rats prebiotic and synbiotic supplementation enhanced IL-10 production in PP compared with controls (PRE 331 $\pm 99 \mathrm{ng} / \mathrm{l}$, SYN $324 \pm 147 \mathrm{ng} / \mathrm{l} v$. control $197 \pm 85 \mathrm{ng} / \mathrm{l}, P<0 \cdot 01)$. Taken together, short- and long-term (AOM-exposed rats) supplementation with OF-enriched IN affected primarily immune functions of the GALT. Long-term supplementation of this prebiotic in rats not exposed to AOM basically affected the spleen. The differences between the systemic and the local immunomodulatory effects of OF-enriched IN in the gut may be related to the underlying mechanisms such as the production of SCFA in the large intestine.

\section{Mechanisms for the effects of inulin/oligofructose on the immune system}

Data from animal studies with different types of dietary fibres suggest that these non-digestible constituents exert distinct immunological effects in the GALT (Lim et al. 1997; Kudoh et al. 1998, 1999; Field et al. 1999). Based on the outcome of the studies described earlier, non-digestible oligosaccharides that classified as prebiotics also affect the GALT. A major outcome of these studies is that OF supplementation increases cell number and cell composition in PP. The underlying mechanism of prebiotic-induced alterations of the cellular structures of PP is not yet known. Substantial experimental data suggest at least three different types of mechanisms of prebiotics that mediate these and other immunological effects (Table 1).

First, IN/OF are known to increase the amount of lactic acidproducing bacteria, especially bifidobacteria (Gibson et al. 1995; Howard et al. 1995; Bouhnik et al. 1999). The IN/OFinduced shift in the intestinal microflora towards bifidobacteria and other SCFA-producing bacteria changes the presence of pathogen-associated molecular patterns in the intestinal lumen including endotoxin or lipopolysaccharides, teichoic acids and unmethylated CpG motifs of DNA (Akira et al. 2001). Immune cells as well as epithelial cells respond via pattern recognition receptors (PRR) such as the toll-like receptors (TLR) to these molecular motifs. TLR signalling results in the activation of $\mathrm{NF}-\kappa \mathrm{B}$ and the secretion of pro-inflammatory cytokines (Abreu, 2003; Cherayil, 2003). Ingestion of bifidobacteria is associated with increased $\operatorname{IgA}$ levels in the small intestine and faeces and ex vivo IgA production by $\mathrm{PP}$ B-lymphocytes (Takahashi et al. 1998; Fukushima et al. 1999; Qiao et al. 2002). One study with dogs supplementing a low dose of OF $(2 \mathrm{~g} / \mathrm{d})$ could not find significant effects on the number of bifidobacteria or on immunological markers (Swanson et al. 2002). This outcome supports the hypothesis that changes in numbers of bifidobacteria induced by OF supplementation are a prerequisite for changes of immunological functions such as $\operatorname{IgA}$ production. In addition to the increase in bacterial cell number, prebiotics promote the increase in bacterial cell wall components as well as DNA derived from luminal bacteria that in turn may stimulate mucosal immune cells.

A second potential mechanism relates to the enhanced production of SCFA in IN/OF-supplemented animals. SCFA are produced by microbial fermentation in the colon with total concentrations ranging from 70 to $140 \mathrm{~mm}$ (Engelhardt et al. 1991) and are rapidly transferred to the bloodstream. Usual SCFA concentrations in the bloodstream are 100-150 $\mu \mathrm{M}$ for 
Table 1. Potential mechanisms of prebiotic-induced immune alterations in the gut

Selective increase/decrease in specific bacteria which modulate cytokine and antibody production

Increase in intestinal SCFA production and enhanced binding

of SCFA to G-coupled protein receptors on leucocytes

Interaction with carbohydrate receptors on leucocytes

acetate, 4-5 $\mu \mathrm{M}$ for propionate and 1-3 $\mu \mathrm{M}$ for butyrate (Wolever et al. 1997). Colonic infusion of butyrate or SCFA resulted in enhanced epithelial proliferation in distant intestinal segments (Kripke et al. 1989; Ichikawa et al. 2002) suggesting that the production of SCFA in the colon induces physiological changes throughout the intestinal tract.

Long-term supplementation of rats with OF-enriched IN increased caecal SCFA concentrations in rats and especially enhanced butyrate levels (Femia et al. 2002). Butyrate is known to suppress lymphocyte proliferation, to inhibit cytokine production of Th1-lymphocytes, to induce T-lymphocyte apoptosis and to upregulate IL-10 production (Säemann et al. 2000; Cavaglieri et al. 2003; Kurita-Ochiai et al. 2003). NF-кB, a central pro-inflammatory transcription factor regulating cytokine mRNA expression, is influenced by butyrate (Inan et al. 2000). In the rat total parenteral nutrition supplemented with SCFA significantly stimulated NK cell cytotoxicity compared to total parenteral nutrition without SCFA (Pratt et al. 1996). Intravenous application of pharmacological doses of acetate also enhanced NK cell cytotoxicity (Ishizaka et al. 1993). Taken together, these data suggest that SCFA as fermentation products of IN/ OF may affect leucocytes within the GALT.

Recently, two receptors for SCFA have been identified on leucocytes, opening up new perspectives for understanding how SCFA may activate leucocytes and induce signal transduction. For the G-protein-coupled receptor GPR43, acetate and propionate have been found to be the most potent ligands (Brown et al. 2003; Nilsson et al. 2003). Butyrate and isobutyrate are more active on the receptor GPR41 (Le Poul et al. 2003). While GPR41 is expressed in a wide range of tissues including neutrophils, GPR43 is highly expressed in immune cells (Brown et al. 2003; Le Poul et al. 2003).

The average concentrations of propionate and butyrate in blood are too low to activate GPR41 or GPR43. However, the blood concentrations reached by acetate are well within the active range for GPR43 (Le Poul et al. 2003). Enhanced SCFA production in the gut after prebiotic supplementation may increase SCFA supply to immune cells located along the GALT (Bach Knudsen et al. 2003) and activate these cells via the SCFA receptors. Such local effects of SCFA may explain in part the observed differences between the systemic and the local immune effects in the gut in IN/OF-supplemented animals and in dogs supplemented with different types of fermentable dietary fibres (Field et al. 1999).

The third mechanism points to interactions of prebiotic carbohydrates with carbohydrate receptors on immune cells. Phagocytic cells, minor subsets of T- and B-lymphocytes and NK cells express the complement receptor 3 (CD11b/CD18; Ross \& Vetvicka, 1993). This receptor mediates cellular cytotoxic reactions against target cells bearing specific carbohydrate structures. Soluble $\beta$-glucans derived from the yeast cell wall are particularly potent stimulator of this receptor. Recently, the $\beta$-glucan receptor dectin-1 on neutrophils, monocytes and macrophages has been identified (Brown \& Gordon, 2001; Herre et al. 2004). This C-type lectin receptor belongs to the PRR, is widely expressed in thymus, spleen and the small intestine, and recognises a variety of $\beta$-1,3-linked and $\beta-1,6$-linked glucans (DP $>7$ ) from fungi and plants. In vitro, the non-digestible oligosaccharides nigerooligosaccharides stimulated NK cell cytotoxicity pointing to a direct effect of this oligosaccharide on NK cells via specific lectin-type receptors (Murosaki et al. 1999). While mannose receptors have also been identified on immune cells (Herre et al. 2004), it is presently not known whether specific fructose receptors exist on immune cells. Fructose in vitro is known to modulate non-opsonic phagocytosis and reactive oxygen species production of phagocytes (Speert et al. 1984; Sehgal et al. 1993).

\section{Conclusions}

Although data from human studies are still scarce, the results from recent animal studies clearly suggest that IN/OF have a strong impact on the immune system, immune cells of the PP being primarily activated by such prebiotics. Data from tumour models further demonstrated that a reduced number of colonic tumours in IN/OF-supplemented animals coincided with enhanced NK cell cytotoxicity. Whether humans with a daily intake of prebiotics also benefit in regard to improved host resistance and reduced colon cancer risk remains to be studied.

\section{Acknowledgements}

Our research is supported by the Commission of the European Communities, Project No. QLRT-1999-00 346, and by the Federal Ministry for Consumer Protection, Food and Agriculture.

\section{References}

Abreu MT (2003) Immunologic regulation of toll-like receptors in gut epithelium. Curr Opin Gastroenterol 19, 559-564.

Abreu-Martin MT \& Targan SR (1996) Regulation of immune responses of the intestinal mucosa. Crit Rev Immunol 16, 277-309.

Akira Sh, Takeda K \& Kaisho T (2001) Toll-like receptors: critical proteins linking innate and acquired immunity. Nat Immunol 2, 675-680.

Bach Knudsen SE, Serena A, Canibe N \& Juntunen KS (2003) New insight into butyrate metabolism. Proc Nutr Soc 62, 81-86.

Bassonga E, Forest V, Pierre F, Bornet F, Perrin P, Meflah K \& Menanteau J (2001) Cytokine mRNA expression in mouse colon: IL15 mRNA is overexpressed and is highly sensitive to a fibre-like dietary component (short-chain fructo-oligosaccharides) in an Apc gene manner. Cytokine 14, 243-246.

Bouhnik Y, Vahedi K, Achour L, et al. (1999) Short-chain fructo-oligosaccharide administration dose-dependently increases fecal bifidobacteria in healthy humans. $J$ Nutr 129, 113-116.

Brown AJ, Goldsworthy SM, Barnes AA, et al. (2003) The orphan G protein-coupled receptors GPR41 and GPR43 are activated by propionate and other short chain carboxylic acids. J Biol Chem 278, 11312-11319.

Brown GD \& Gordon S (2001) A new receptor for $\beta$-glucans. Nature 413, 36-37.

Buddington KK, Donahoo JB \& Buddington RK (2002) Dietary oligofructose and inulin protect mice from enteric and systemic pathogens and tumor inducers. J Nutr 132, 472-477.

Bunout D, Hirsch S, de la Maza MP, et al. (2002) Effects of prebiotics on the immune response to vaccination in the elderly. $J$ Parenter Enteral Nutr 26, 372-376. 
Calder PC, Field CJ \& Gill HS (2002) Nutrition and Immune Function. Wallingford, UK: CABI Publishing.

Cavaglieri CR, Nishiyama A, Fernandes LC, Curi R, Miles EA \& Calder PC (2003) Differential effects of short-chain fatty acids on proliferation and production of pro- and anti-inflammatory cytokines by cultured lymphocytes. Life Sci 73, 1683-1690.

Cherayil BJ (2003) How not to get bugged by bugs: mechanisms of cellular tolerance to microorganisms. Curr Opin Gastroenterol 19, 572-577.

Chiang BL, Sheih YH, Wang LH, Liao CK \& Gill HS (2000) Enhancing immunity by dietary consumption of a probiotic lactic acid bacterium (Bifidobacterium lactis HN019): optimization and definition of cellular immune responses. Eur J Clin Nutr 54, 849-855.

Delzenne NM (2003) Oligosaccharides: state of the art. Proc Nutr Soc 62, $177-182$.

Duggan Ch, Penny ME, Hibberd P, Gil A, Huapaya A, Cooper A, Coletta F, Emenhiser C \& Kleinman RE (2003) Oligofructose-supplemented infant cereal: 2 randomized, blinded, community-based trials in Peruvian infants. Am J Clin Nutr 77, 937-942.

Engelhardt W, Busche R, Gross G \& Rechkemmer G (1991) Absorption of short chain fatty acids: mechanisms and regional differences in the large intestine. In Physiological and Clinical Aspects of Short-Chain Fatty Acids, pp. 60-62 [JH Cummings, JL Rombeau and T Sakata, editors]. Cambridge, UK: Cambridge University Press.

Femia AP, Luceri C, Dolara P, et al. (2002) Antitumorigenic activity of the prebiotic inulin enriched with oligofructose in combination with the probiotics Lactobacillus rhamnosus and Bifidobacterium lactis on azoxymethane-induced colon carcinogenesis in rats. Carcinogenesis 23, 1953-1960.

Field CJ, McBurney MI, Massimino S, Hayek MG \& Sunvold GD (1999) The fermentable fiber content of the diet alters the function and composition of canine gut associated lymphoid tissue. Vet Immunol Immunopathol 72, 325-341.

Flickinger EA, Van Loo J \& Fahey GC (2003) Nutritional responses to the presence of inulin and oligofructose in the diets of domesticated animals: a review. Crit Rev Food Sci Nutr 43, 19-60.

Franck A (2002) Technological functionality of inulin and oligofructose. Br J Nutr 87, S287-S291.

Fukushima Y, Kawata Y, Mizumachi K, Kurisaki J \& Mitsuoka T (1999) Effect of bifidobacteria feeding on fecal flora and production of immunoglobulins in lactating mouse. Int J Food Microbiol 46, 193-197.

Gaskins HR, Mackie RI, May T \& Garleb KA (1996) Dietary fructo-oligosaccharide modulates large intestinal inflammatory responses to Clostridium difficile in antibiotic-compromised mice. Microb Ecol Health Dis 9, 157-166.

Gibson GR \& Roberfroid MB (1995) Dietary modulation of the human colonic microbiota: introducing the concept of prebiotics. J Nutr 125, $1401-1412$.

Gibson GR, Beatty EB, Wang X \& Cummings JH (1995) Selective stimulation of bifidobacteria in the human colon by oligofructose and inulin. Gastroenterology 108, 975-982.

Grizard D \& Barthomeuf Ch (1999) Non-digestible oligosaccharides used as prebiotic agents: mode of production and beneficial effects on animal and human health. Reprod Nutr Dev 39, 563-588.

Guigoz Y, Rochat F, Perruisseau-Carrier G, Rochat I \& Schiffrin EJ (2002) Effects of oligosaccharide on the faecal flora and non-specific immune system in elderly people. Nutr Res 22, 13-25.

Herich R, Révajová V, Levkut M, Bomba A, Nemcová R, Guba P \& Gancarčiková S (2002) The effect of Lactobacillus paracasei and Raftilose P95 upon the non-specific immune response of piglets. Food Agric Immunol 14, 171-179.

Herre J, Gordon S \& Brown GD (2004) Dectin-1 and its role in the recognition of $\beta$-glucans by macrophages. Mol Immunol 40, 869-876.

Hosono A, Ozawa A, Kato R, Ohnishi Y, Nakanishi Y, Kimura T \& Nakamura R (2003) Dietary fructooligosaccharides induce immunoregulation of intestinal IgA secretion by murine Peyer's patch cells. Biosci Biotechnol Biochem 67, 758-764.
Howard MD, Gordon DT, Garleb KA \& Kerley MS (1995) Dietary fructooligosaccharide, xylooligosaccharide and gum arabic have variable effects on cecal and colonic microbiota and epithelial cell proliferation in mice and rats. $J$ Nutr 125, 2604-2609.

Ichikawa H, Shineha R, Satomi S \& Sakata T (2002) Gastric or rectal instillation of short-chain fatty acids stimulates epithelial cell proliferation of small and large intestine in rats. Dig Dis Sci 47, $1141-1146$.

Iijima H, Takahashi I \& Kiyono H (2001) Mucosal immune network in the gut for the control of infectious diseases. Rev Med Virol 11, 117-133.

Inan MS, Rasoulpour RJ, Yin L, Hubbard RK, Rosenberg DW \& Giardina C (2000) The luminal short-chain fatty acid butyrate modulates NFkappaB activity in a human colonic epithelial cell line. Gastroenterology 118, 724-734.

Ishizaka S, Kikuchi E \& Tsujii T (1993) Effects of acetate on human immune system. Immunopharmacol Immunotoxicol 15, 151-162.

Janeway CA, Travers P, Walport W \& Shlonichik M (2001) Immunobiology. In The Immune System in Health and Disease, 5th ed. New York: Taylor \& Francis Books.

Jankovic D, Liu Z \& Gause WC (2001) Th1- and Th2-cell commitment during infectious disease: asymmetry in divergent pathways. Trends Immunol 22, 450-457.

Kaur N \& Gupta AK (2002) Applications of inulin and oligofructose in health and nutrition. J Biosci 27, 703-714.

Kelly-Quagliana KA, Nelson PD \& Buddington RK (2003) Dietary oligofructose and inulin modulate immune functions in mice. Nutr Res $\mathbf{2 3}$, 257-267.

Kripke SA, Fox AD, Berman JM, Settle RG \& Rombeau JL (1989) Stimulation of intestinal mucosal growth with intracolonic infusion of shortchain fatty acids. $J$ Parenter Enteral Nutr 13, 109-116.

Kudoh K, Shimizu J, Wada M, Takita T, Kanke Y \& Innami S (1998) Effect of indigestible saccharides on B lymphocyte response of intestinal mucosa and cecal fermentation in rats. J Nutr Sci Vitaminol 44, $103-112$.

Kudoh K, Shimizu J, Ishiyama A, Wada M, Takita T, Kanke Y \& Innami S (1999) Secretion and excretion of immunoglobulin A to cecum and feces differ with type of indigestible saccharides. J Nutr Sci Vitaminol 45, 173-181.

Kurita-Ochiai T, Amano S, Fukushima K \& Ochiai K (2003) Cellular events involved in butyric acid-induced $\mathrm{T}$ cell apoptosis. J Immunol 171, 3576-3584.

Le Poul E, Loison C, Struyf S, et al. (2003) Functional characterization of human receptors for short chain fatty acids and their role in polymorphonuclear cell activation. J Biol Chem 278, 25481-25489.

Lim BO, Yamada K, Nonaka M, Kuramoto Y, Hung P \& Sugano M (1997) Dietary fibers modulate indices of intestinal immune function in rats. $J$ Nutr 127, 663-667.

MacDonald TT (2003) The mucosal immune system. Parasite Immunol 25, 235-246.

McGuirk P \& Mills KHG (2002) Pathogen-specific regulatory T cells provoke a shift in the Th1/Th2 paradigm in immunity to infectious diseases. Trends Immunol 23, 450-455.

Manhart N, Spittler A, Bergmeister H, Mittlböck M \& Roth E (2003) Influence of fructooligosaccharides on Peyer's patch lymphocyte numbers in healthy and endotoxemic mice. Nutrition 19, 657-660.

Mowat AMcI (2003) Anatomical basis of tolerance and immunity in intestinal antigens. Nat Rev Immunol 3, 331-341.

Mowat AMcI \& Viney JL (1997) The anatomical basis of intestinal immunity. Immunol Rev 156, 145-166.

Murosaki S, Muroyama K, Yamamoto Y, Kusaka H, Liu T \& Yoshika Y (1999) Immunopotentiating activity of nigerooligosaccharides for the $T$ helper 1-like immune response in mice. Biosci Biotechnol Biochem 63, 373-378.

Nilsson NE, Kotarsky K, Owman C \& Olde B (2003) Identification of a free fatty acid receptor, FFA2R, expressed on leucocytes and activated by short-chain fatty acids. Biochem Biophys Res Commun 303, 1047-1052. 
Pierre F, Perrin P, Champ M, Bornet F, Meflah K \& Menanteau J (1997) Short-chain fructo-oligosaccharides reduce the occurrence of colon tumors and develop gut-associated lymphoid tissue in Min mice. Cancer Res 57, 225-228.

Pierre F, Perrin P, Bassonga E, Bornet F, Meflah K \& Menanteau J (1999) $\mathrm{T}$ cell status influences colon tumor occurrence in Min mice fed short chain fructo-oligosaccharides as a diet supplement. Carcinogenesis 20, 1953-1956.

Pratt VC, Tappenden KA, McBurney MI \& Field CJ (1996) Short-chain fatty acid-supplemented total parenteral nutrition improves nonspecific immunity after intestinal resection in rats. J Parenter Enteral Nutr 20, 264-271.

Qiao H, Duffy LC, Griffiths E, Dryja D, Leavens A, Rossman J, Rich G, Riepenhoff-Talty M \& Locniskar M (2002) Immune responses in rhesus rotavirus-challenged $\mathrm{Balb} / \mathrm{c}$ mice treated with bifidobacteria and prebiotic supplements. Pediatr Res 51, 750-755.

Roller M, Rechkemmer G \& Watzl B (2004a) Prebiotic inulin enriched with oligofructose in combination with the probiotics Lactobacillus rhamnosus and Bifidobacterium lactis modulates intestinal immune functions in rats. J Nutr 134, 153-156.

Roller M, Femia AP, Caderni G, Rechkemmer G \& Watzl B (2004b) Intestinal immunity of rats with azoxymethane-induced colon cancer is modulated by inulim enriched with oligofructose combined with Lactobacillus rhamnosus and Bifidobacterium longis. Br J Nutr 92, 931-938.

Ross GD \& Větvička V (1993) CR3 (CD11b, CD18): a phagocyte and NK cell membrane receptor with multiple ligand specificities and functions. Clin Exp Immunol 92, 181-184.

Säemann MD, Böhmig GA, Österreicher CH, Burtscher H, Parolini O, Diakos Ch, Stöckl J, Hörl WH \& Zlabinger GJ (2000) Anti-inflammatory effects of sodium butyrate on human monocytes: potent inhibition of IL-12 and up-regulation of IL-10 production. FASEB J 14, 2380-2382.

Schley PD \& Field CJ (2002) The immune-enhancing effects of dietary fibres and prebiotics. Br J Nutr 87, S221-S230.

Schneeman BO (1999) Fiber, inulin and oligofructose: similarities and differences. J Nutr 129, 1424S-1427S
Sehgal G, Zhang K, Todd RF 3rd, Boxer LA \& Petty HR (1993) Lectin-like inhibition of immune complex receptor-mediated stimulation of neutrophils. Effects on cytosolic calcium release and superoxide production. J Immunol 150, 4571-4580.

Sheih YH, Chiang BL, Wang LH, Liao CK \& Gill HS (2001) Systemic immunity-enhancing effects in healthy subjects following dietary consumption of the lactic acid bacterium Lactobacillus rhamnosus HN001. J Am College Nutr 20, 149-156.

Spahn TW \& Kucharzik T (2004) Modulating the intestinal immune system: the role of lymphotoxin and GALT organs. Gut 53, 456-465.

Speert DP, Eftekhar F \& Puterman ML (1984) Nonopsonic phagocytosis of strains of Pseudomonas aeruginosa from cystic fibrosis patients. Infect Immun 43, 1006-1011.

Swanson KS, Grieshop ChM, Flickinger EA, Bauer LL, Healy HP, Dawson KA, Merchen NR \& Fahey GC Jr (2002) Supplemental fructooligosaccharides and mannanoligosaccharides influence immune function, ileal and total tract nutrient digestibilities, microbial populations and concentrations of protein catabolites in the large bowel of dogs. J Nutr 132, 980-989.

Takahashi T, Nakagawa E, Nara T, Yajima T \& Kuwata T (1998) Effects of orally ingested Bifidobacterium longum on the mucosal $\mathrm{IgA}$ response of mice to dietary antigens. Biosci Biotechnol Biochem 62, 10-15.

van Loo J, Coussement P, De Leenheer L, Hoebregs H \& Smits G (1995) On the presence of inulin and oligofructose as natural ingredients in the Western diet. Crit Rev Food Sci Nutr 35, 525-552.

van Loo J, Cummings J, Delzenne N, et al. (1999) Functional food properties of non-digestible oligosaccharides: a consensus report from the ENDO project (DGXII AIRII-CT94-1095). Br J Nutr 81, 121-132.

Watzl B, Bub A, Blockhaus M, Herbert BM, Lührmann PM, NeuhäuserBerthold M \& Rechkemmer G (2000) Prolonged tomato juice consumption has no effect on cell-mediated immunity of well-nourished elderly men and women. J Nutr 130, 1719-1723.

Wolever TM, Josse RG, Leiter RA \& Chiasson JL (1997) Time of day and glucose tolerance status affect serum short-chain fatty acid concentrations in humans. Metabolism 46, 805-811. 